Revista Interdisciplinaria de Humanidades, Educación, Ciencia y Tecnología

Año VII. Vol. VII. N². Edición Especial II. 2021

Hecho el depósito de ley: pp201602FA4721

ISSN-L: 2542-3029; ISSN: 2610-802X

Universidad Nacional Experimental Francisco de Miranda (UNEFM). Santa Ana de Coro. Venezuela

Alba Briggithe Jiménez-Díaz; Cecilia Ivonne Narváez-Zurita

DOI $10.35381 / \mathrm{cm} . v 7 \mathrm{i} 2.507$

\title{
Gestión financiera en tiempos de COVID-19 para Cooperativas de producción y mercadeo
}

\section{COVID-19 Time Financial Management for Production and Marketing Cooperatives}

\author{
Alba Briggithe Jiménez-Díaz \\ alba.jimenez.05@est.ucacue.edu.ec \\ Universidad Católica De Cuenca, Cuenca \\ Ecuador \\ https://orcid.org/0000-0002-1891-0315 \\ Cecilia Ivonne Narváez-Zurita \\ inarvaez@ucacue.edu.ec \\ Universidad Católica de Cuenca, Cuenca \\ Ecuador \\ https://orcid.org/0000-0002-7437-9880
}

Recibido: 20 de mayo de 2021

Aprobado: 25 de agosto de 2021 


\title{
RESUMEN
}

La pandemia por COVID-19 cada día genera más efectos en distintos campos de la humanidad, y en los negocios, por tanto, su incidencia se ve reflejada en la contabilidad y en las finanzas. En este contexto, la mayoría de sectores productivos del Ecuador sufrirán pérdidas de liquidez y rentabilidad incalculables. Por ello, existe la necesidad de diseñar planes de continuidad que garanticen la sobrevivencia de las empresas ante los riegos internos y externos que se están presentando. En esta investigación de tipo descriptiva con diseño no experimental, se analiza el caso de la Cooperativa de Producción y Mercadeo de teja y ladrillo 27 de Junio, la misma que presenta bajos niveles de liquidez, para solventar este problema se propone el diseño de un plan de continuidad a fin de que la organización continúe prestando sus servicios de manera habitual y no interrumpa el desarrollo normal de sus operaciones.

Descriptores: Administración de empresas; administración financiera; política financiera. (Palabras tomadas de Tesauro Unesco).

\begin{abstract}
The COVID-19 pandemic every day generates more effects in different fields of humanity, and in business, therefore, its incidence is reflected in accounting and finances. In this context, most of Ecuador's productive sectors will suffer incalculable liquidity and profitability losses. Therefore, there is a need to design continuity plans that guarantee the survival of companies in the face of internal and external risks that are occurring. In this descriptive research with non-experimental design, the case of the Cooperativa de Producción y Mercadeo of tile and brick June 27 is analyzed, the same one that presents low levels of liquidity, to solve this problem the design of a plan is proposed continuity so that the organization continues to provide its services on a regular basis and does not interrupt the normal development of its operations.
\end{abstract}

Descriptors: Business management; financial administration; financial policy. (Words taken from UNESCO o Thesaurus). 


\section{INTRODUCCIÓN}

Durante los últimos años el entorno financiero ha presentado importantes transformaciones en la gestión de los recursos económicos, lo que genera mayor competencia entre empresas, destacándose en este proceso evolutivo la incorporación de la tecnología mediante paquetes informáticos y sistemas bancarios electrónicos que han contribuido de manera significativa en la optimización de las operaciones de tesorería y la recurrencia de créditos e inversiones financieras.

A pesar de estos avances importantes en el ámbito tecnológico, ha sido imposible detener la crisis sanitaria mundial causada por la pandemia COVID-19, la misma que representa un reto no solo para el sistema de salud mundial, sino también, para las empresas que se han visto afectadas en gran medida. Esta situación ha generado pérdidas en la mayoría de las actividades económicas, más aún en las pequeñas empresas que dejaron de percibir recursos económicos al disminuir sus ventas, debido a las medidas de confinamiento y, por consiguiente, disminución parcial o total de operaciones según el caso. Ante este panorama, se evidencia la necesidad de gestionar de forma adecuada los recursos de la empresa, para ello, se debe tomar en cuenta el pasado, el presente y el futuro, para evitar errores, evaluar riesgos u oportunidades futuras encaminadas a lograr mayores beneficios y niveles altos de rentabilidad.

En Ecuador la emergencia sanitaria ha llevado a una crisis económica sin precedentes a las empresas, más del $85 \%$ han generado pérdidas en sus ventas; entre otras dificultades se evidencian los problemas para cobrar cuentas pendientes a sus clientes y para cumplir con las obligaciones contraídas con sus proveedores, debido a estas dificultades la mayoría de las empresas se han visto en la necesidad de despedir a sus trabajadores o reducir los sueldos. El mayor reto que atraviesan en la actualidad es la generación de dinero para cubrir las obligaciones inmediatas (Coba, 2020).

En este sentido, las medidas adoptadas por el gobierno ecuatoriano para contener la propagación del COVID-19 han provocado fuertes perturbaciones en el aprovisionamiento y distribución de productos, lo que ha dado paso a la escasez de 
inventarios, reducción de la demanda por parte de los clientes y retrasos en la cadena de suministros, situaciones que están impactado de manera drástica en todas las ramas de producción y servicios a nivel nacional. El sector de la economía popular y solidaria (EPS) no se encuentra ajeno a esta realidad, varios negocios se declararon en quiebra, mientras que, otros se quedaron sin disponible para continuar con sus operaciones, por lo que tuvieron que reducir el número de trabajadores y en unos casos operar en la modalidad de teletrabajo de forma parcial.

En el caso particular de la Cooperativa de Producción y Mercadeo de Teja y Ladrillo 27 de Junio, organización que forma parte de la EPS, las ventas disminuyeron de manera significativa, por lo que su actividad de producción de teja presentó pérdidas durante el año 2020, a esta realidad se suma la falta de fuentes propias de financiamiento, lo que dificulta aún más su proceso de recuperación. Este panorama de crisis obliga a que todas las organizaciones de la EPS incorporen acciones y gestionen sus finanzas en el marco de las políticas públicas establecidas por el gobierno central y los gobiernos locales para fortalecer y consolidar este sector (Secretaria Técnica Planifica Ecuador, 2020).

Por lo indicado, la investigación responde a la siguiente interrogante: ¿cómo hacer frente a los retos de liquidez en la Cooperativa de Producción y Mercadeo de teja y ladrillo 27 de Junio en el cantón Catamayo tras el COVID-19?, y, como objetivo general se establece: diseñar un plan de continuidad para la Cooperativa de Producción y Mercadeo de Teja y Ladrillo 27 de Junio que permita mejorar la liquidez bajo el contexto de la pandemia de COVID-19. Para lograrlo se establecen como objetivos específicos fundamentar de manera teórica la gestión financiera y los efectos causados por el COVID19 en la liquidez empresarial con el uso de criterios nacionales e internacionales; diagnosticar la liquidez de la Cooperativa de Producción y Mercadeo de Teja y Ladrillo 27 de Junio durante el año 2020; y, establecer los componentes para el diseño de un plan de continuidad que mitigue los impactos financieros del COVID-19. 


\section{Referencial teórico}

\section{Enfoque de la gestión financiera en las organizaciones}

La gestión financiera es un área clave en las empresas, su primordial objetivo es maximizar el valor de las organizaciones, establecer bajos costos de financiamiento, aumento de rentabilidad de activos y una adecuada eficiencia de liquidez, mediante la implementación de herramientas de análisis económico - financiero para las organizaciones y la integración de acciones por parte del gestor financiero para maximizar los recursos y beneficios económicos (Erazo-Álvarez, López-Intriago, Narváez-Zurita, \& Moreno, 2020).

La gestión financiera es importante para la generación de ingresos, permite reducir los costos con un manejo eficiente de los recursos de las organizaciones, a la vez, gestiona aspectos significativos como la inversión y el financiamiento (Zambrano-Vera, y otros, 2018). Las funciones de la gestión financiera empiezan desde la elaboración de los pronósticos y presupuestos, esto permite determinar el total de fondos que serán necesarios para la empresa, con la finalidad de identificar fuentes de financiamiento y ejecutar de forma eficiente la asignación de fondos entre todas las actividades a ejecutar. Finalmente, el control financiero, permite distribuir las fuentes de financiamiento, vigilar el presupuesto y elaborar los informes.

En este sentido, el administrador financiero es el responsable de asignar los recursos financieros a cada departamento de la empresa, con el propósito de combinar de manera efectiva el financiamiento de sus activos y las funciones que se pueden ejecutar de manera diaria u ocasional. Las funciones diarias permiten administrar los créditos, llevar un control de inventarios, receptar y desembolsar fondos; mientras que, las funciones ocasionales se enfocan en la emisión de acciones y bonos, así como, la aplicación de presupuestos de capital que posibilitan tomar decisiones en cuanto al reparto de dividendos (Fajardo-Ortiz \& Soto-González, 2018). Para comprender la gestión financiera es necesario conocer las fases que la integran: 
a) Fase de planificación: se encarga de definir actividades de funcionamiento, apoyándose en la elaboración de planes estratégicos, planes operativos y presupuestos.

b) Fase de decisión y control: se sustenta en el desarrollo de un proceso de evaluación y proyección encargado de controlar las acciones realizadas para respaldar la toma de decisiones.

El modelo de gestión financiera se enfoca en tres primordiales hitos: procesos, individuos y tecnología, para que este sea adecuado, debe tener las siguientes características: flexible, innovador, interactivo y sistemático y su ejecución e implementación debe ser eficiente y eficaz.

En este contexto, (Palomo-Urrutia, 2016) precisa que la gestión financiera en las organizaciones puede estructurarse en distintos modelos, tales como:

Modelo de gestión por resultados o administración por objetivos: este modelo plantea que para aumentar la eficiencia es importante asignar mayor responsabilidad a los funcionarios de la organización. Permite integrar la necesidad de la empresa para lograr sus objetivos y generar ganancia, por lo que es considerado un modelo dinámico y flexible, sus principales características son la exigencia y el equilibrio de la administración. Modelo de gestión por procesos: corresponde al planeamiento de actividades con la finalidad de mejorar los procesos claves de desempeño en el negocio.

Modelo de gestión de la calidad total: busca satisfacer las necesidades del cliente con el diseño de productos y servicios promovidos por la mejora constante en todos los procesos.

Modelo Balanced ScoreCard: conocido como cuadro de mando integral, el mismo amplía la perspectiva de la empresa con relación a las decisiones económicas y financieras, por cuanto busca cambiar los sistemas de medición tradicionales para evaluar los resultados a futuro, esto permite que el plan estratégico sea trasladado a la acción, para que la alta dirección esté informada en tiempo real sobre el logro de las metas preestablecidas. 


\section{Soluciones financieras en tiempos de crisis}

Los problemas que conllevan la crisis del COVID 19, generan la necesidad de plantearse soluciones financieras diversas que permitan nuevas oportunidades para las pequeñas empresas, al respecto, la Compañía (Efiempresa, 2021) presenta las soluciones que se detallan a continuación:

a) La rentabilidad tecnológica que consiste en incorporar recursos tecnológicos en una organización, para garantizar su nivel competitivo a nivel nacional e internacional, ya que optimiza procesos, disminuye posibles errores, brinda un mejor servicio y permite crear modelos y estrategias de control en un espacio de tiempo corto.

b) Incremento de la rentabilidad y/o utilidad, es otra solución que proporciona beneficios, permite que las organizaciones cuenten con un adecuado sistema contable que facilite el control de los costos con un máximo aprovechamiento de sus recursos, además vuelve eficiente la cadena de distribución de más productos, y mantiene los mismos gastos.

c) Incremento de la liquidez mediante la aplicación de sistemas de control de stock que contribuyen con el control de caja, reducen el costo de materiales innecesarios, automatizan periodos y montos tanto para cobros como para pagos.

d) Optimización del capital de trabajo consiste en establecer estrategias para mejorar la entrada y salida de dinero, un manejo disciplinado de los cobros y pagos, optimizar la rotación de costos ocultos como los inventarios y activos corrientes.

e) Liderazgo en costos globales consiste en un riguroso control de costos que permite identificar riesgos y aplicar medidas urgentes para conservar el efectivo a corto y mediano plazo.

f) Concentración de efectivo que se enfoca en el poder de negociación con las instituciones financieras para llegar a acuerdos de pago, con intereses bajos, sin dañar el historial crediticio y mantener un impacto positivo en la liquidez de la empresa. 
g) Proyección del flujo del efectivo que permite evaluar escenarios reales a corto y mediano plazo, se proyecta el ingreso y la salida de efectivo para garantizar confianza a los clientes y proveedores.

En estos tiempos de crisis se debe diseñar planes de continuidad en las empresas para asegurar su prolongación en el tiempo, según la firma Deloitte, al contar con este plan de continuidad se reduce de forma significativa el riesgo de quedar fuera del mercado luego de un desastre. Para este efecto se deben seguir los pasos que se muestran en la figura 1.

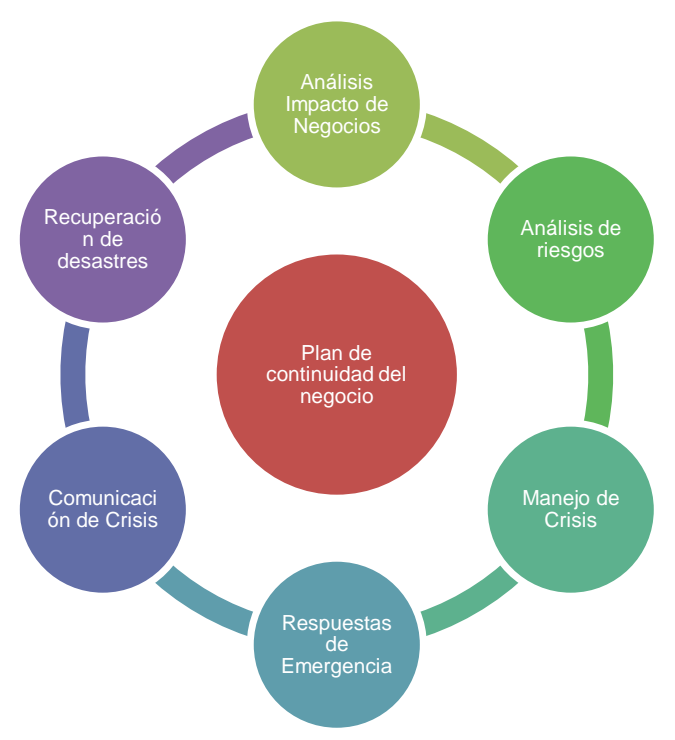

Figura 1. Plan de continuidad de negocios.

Fuente: García-Nava \& Paredes-Hernández (2018).

Entre los beneficios de contar con un plan de continuidad del negocio están la concientización de amenazas; protección a las personas y a la reputación empresarial, mejoras en la capacidad de recuperación de la cadena de suministros, acatamiento de las demandas legales y de los consumidores y posibilidad de responder a sucesos mayores de manera efectiva y con procesos seguros (Deloitte, 2017). También se debe 
considerar que ante la crisis actual existen ajustes que deben realizarse en los procesos contables, entre otros están los cambios en los plazos y métodos de recuperación de cartera vencida, inventarios, propiedad, planta y equipo que han perdido su valor comercial de manera significativa (Tax Service \& TFC Consultores Corporativos, 2020).

\section{Administración del riesgo de liquidez en la economía popular y solidaria}

La economía popular y solidaria (EPS) es el conjunto de formas y prácticas económicas que son gestionadas por sus propietarios, se privilegia al ser humano como sujeto y fin de su actividad, este sistema económico se encuentra regido por la Superintendencia de Economía Popular y Solidaria (SEPS) en el Ecuador. En las empresas que se encuentran dentro de la EPS, uno de los riesgos provocados por la pandemia del COVID-19 es el no sintomático, entendiéndose como tal al riesgo de liquidez, el mismo que comprende los riesgos de mercado, crédito y operacionales lo que genera inconvenientes en todos los sectores; por lo tanto, la dirección de riesgo se vuelve una etapa fundamental en la gestión económica y financiera de las empresas, las organizaciones deben fortalecer sus planes estratégicos con la finalidad de estar preparados ante diversos contingentes (Comisión Económica para América Latina y el Caribe (CEPAL), 2020).

Para evitar el riesgo de liquidez en una empresa, es necesario aplicar mecanismos que reduzcan el riesgo, entre ellos se encuentran la rotación del inventario tan rápido como sea necesario, para evitar el desabastecimiento que provoque detrimentos en las ventas; aplicar técnicas de cobro para recuperar cuentas vencidas tan rápido como sea posible sin perder clientes; y, cancelar a los proveedores lo más lento posible sin dañar la calificación crediticia de la institución. En este proceso es necesario considerar el tiempo que pasa desde que la empresa realiza un gasto para adquirir mercadería hasta el momento en que se registra el ingreso por su venta, a este proceso se lo conoce como el ciclo de conversión del efectivo, lo normal sería que este ciclo de efectivo sea menor a 100 días, los componentes son: edad promedio de inventario, periodo promedio de cobro y periodo promedio de pago. Para calcular el ciclo de conversión del efectivo se utiliza la 
siguiente fórmula de cálculo: $\mathrm{CCE}=\mathrm{EPI}+\mathrm{PPC}-\mathrm{PPP}$ (Ciclo de conversión del efectivo=Edad promedio de inventario + periodo promedio de cobro - periodo promedio de pago). En la figura 2, se presenta una línea de tiempo horizontal que permite visualizar el tiempo que dura la conversión del efectivo

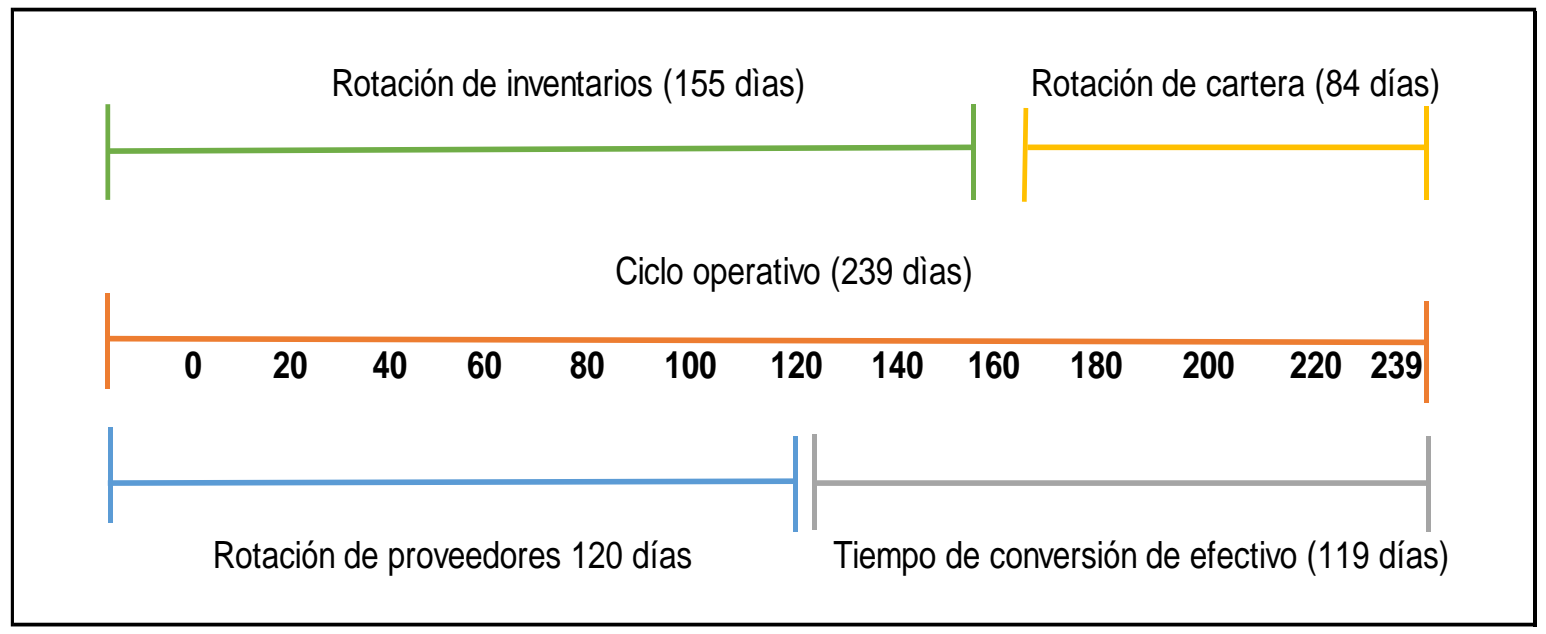

Figura 2. Línea de tiempo para conversión del efectivo.

Fuente: Lawrence \& Chad (2016).

Los riesgos de liquidez en las organizaciones de la economía popular y solidaria deben ser analizad-os para determinar el proceso productivo y mantener en marcha sus operaciones, además, esto proporciona seguridad al demostrar la capacidad de pago, evita que se rematen los activos a precios castigados por falta de fondos y la caída en financiamientos con intereses elevados. La ventaja de realizar un análisis de riesgo radica en q-ue permite determinar la eventualidad de un suceso y la magnitud de su consecuencia para prevenir amenazas y descubrir oportunidades.

Por otra parte, es importante realizar un análisis financiero que es un proceso que recopila, interpreta, compara y estudia la información presentada en los estados financieros. Esto involucra cálculos, análisis en porcentajes, tendencias e indicadores que 
permiten evaluar el desempeño económico y financiero de una organización que posibilita a directivos e inversores tomar decisiones.

Para realizar un análisis financiero se debe considerar como herramientas los estados financieros, información contable complementaria, administrativa y de mercado, puesto que los resultados son de interés de la administración de la empresa, inversionistas, bancos acreedores, cámaras de comercio y, administradoras de impuestos (ZapataSánchez, 2017). El análisis financiero se clasifica en:

1. Análisis vertical que es un método estático que estudia cada cuenta del estado financiero objeto de estudio, el mismo que se presenta en porcentajes relacionados con cada partida de una cuenta o subgrupos de cuentas. A continuación, se detalla su cálculo con relación en cada cuenta:

Análisis Vertical $=$ Valor de la cuenta/ valor del subgrupo *100. Para obtener el porcentaje del subgrupo se aplica así: valor del subgrupo/ valor del grupo*100 (A.V=VC/VS*100).

2. Análisis horizontal es un procedimiento dinámico que busca determinar la variación que ha sufrido cada partida, se compara estados financieros homogéneos en dos o más periodos consecutivos que reflejen el aumento 0 disminución de una cuenta. Para determinar la variación absoluta se procede a calcular la diferencia entre el periodo dos con respecto al periodo uno, es decir, periodo dos menos periodo uno. Para establecer la variación relativa o porcentaje se divide el aumento o disminución con el valor del año base y se lo multiplica por 100.

Por otra parte, en el mundo de las finanzas se aplican los indicadores financieros que otorgan información relevante sobre los resultados que se reflejan en los estados financieros, pues su análisis e interpretación cumplen un papel importante en la organización, ya que los resultados que se obtienen en porcentajes evidencian el nivel de confianza como en el caso de los indicadores de liquidez que muestran la capacidad 
de pago a corto plazo. Es importante mencionar también las razones de endeudamiento y las razones de rentabilidad, la primera que mide el nivel de participación de los acreedores en el financiamiento de la empresa, que determina la ventaja o desventaja del endeudamiento y la segunda que mide la efectividad del control de costos y gastos para obtener rentabilidad.

Los indicadores de liquidez, endeudamiento y rentabilidad se presentan en la tabla 1. Además de los indicadores, se debe contar con estrategias, estas son reglas que permiten determinar las acciones apropiadas para cumplir las metas y fines en la empresa, y establecer las prioridades en la asignación de recursos vitales, al comprender las metas, los programas y planes de acción (Cárdenas-Carreño, Erazo-Álvarez, Narváez-Zurita, \& Andrade-Mena, 2021). Los resultados que se reflejan luego de aplicar los indicadores no siempre representan entradas inmediatas de dinero ni gastos, puesto que por las ventas realizadas no se cobran de manera inmediata, estos quedan registrados como derechos de cobro. 
Revista Interdisciplinaria de Humanidades, Educación, Ciencia y Tecnología

Año VII. Vol. VII. N². Edición Especial II. 2021

Hecho el depósito de ley: pp201602FA4721

ISSN-L: 2542-3029; ISSN: 2610-802X

Universidad Nacional Experimental Francisco de Miranda (UNEFM). Santa Ana de Coro. Venezuela

Alba Briggithe Jiménez-Díaz; Cecilia Ivonne Narváez-Zurita

\section{Tabla 1.}

Indicadores financieros.

\begin{tabular}{|c|c|c|}
\hline Indicadores & Fórmulas & Medición \\
\hline \multirow{7}{*}{$\frac{\mathbb{Q}}{\frac{0}{3}}$} & Razón corriente $=\frac{\text { Activo corriente }}{\text { Pasivo corriente }}$ & $\begin{array}{l}\text { Controla la disponibilidad en corto plazo entre más } \\
\text { alto se considera mejor }\end{array}$ \\
\hline & & Estandar: De 1 a 1,5 \\
\hline & Capital de trabajo= Activo corriente-Pasivo corriente & \\
\hline & & Mide los resultados de la razòn corriente \\
\hline & & Estandar: $>1$ \\
\hline & Prueba ácida $=\frac{\text { Activo corriente- Inventario }}{\text { Pasivo corriente }}$ & $\begin{array}{l}\text { Mide la capacidad que tiene una empresa para } \\
\text { cancelar sus obligaciones corrientes }\end{array}$ \\
\hline & & Estandar: De 0,5 a 1 \\
\hline \multirow{7}{*}{ 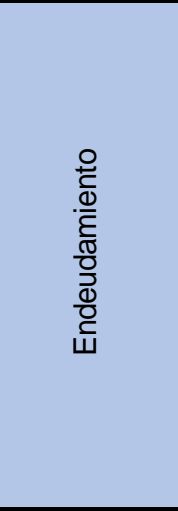 } & Nivel de endeudamiento $=\frac{\text { Pasivo total }}{\text { Activo total }} * 100$ & $\begin{array}{l}\text { Mide los fondos totales que han sido } \\
\text { proporcionados por los acreedores }\end{array}$ \\
\hline & & Estandar: $<50 \%$ \\
\hline & Estructura del capital $=\frac{\text { Pasivo total }}{\text { Patrimonio }} * 100$ & $\begin{array}{l}\text { Mide los aportes de los proveedores y acreedores } \\
\text { por cada dólar aportado por los propietarios }\end{array}$ \\
\hline & & Estandar: $>50 \%$ \\
\hline & Impacto de carga financiera $=\frac{\text { Gastos financieros }}{\text { Ventas }}$ & $\begin{array}{l}\text { Representa los gastos financieros en relación a los } \\
\text { ingresos operacionales en porcentajes }\end{array}$ \\
\hline & Concentracion de endeudamiento corto plazo $=\frac{\text { Pasivo corriente }}{\text { Pasivo total }} * 100$ & $\begin{array}{l}\text { Estandar: De } 3 \text { a } 4 \% \\
\text { Indica que el porcentaje de los pasivos tiene un } \\
\text { vencimiento menor a un año }\end{array}$ \\
\hline & & Estandar: $<50 \%$ \\
\hline \multirow{5}{*}{ 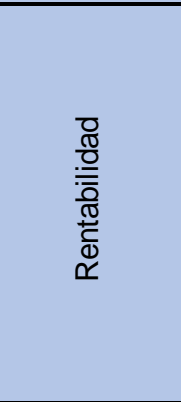 } & Margen de utilidad bruto $=\frac{\text { Utilidad bruta }}{\text { Ventas netas }} * 100$ & $\begin{array}{l}\text { Establece en forma porcentual cada dólar que } \\
\text { surge despuès que la venta pagó sus bienes }\end{array}$ \\
\hline & Margen bruto de utilidad neta $=\frac{\text { Utilidad neta }}{\text { Ventas }} * 100$ & $\begin{array}{l}\text { Estandar: } 30 \% \text { a } 40 \% \\
\text { Refleja en porcentajes la utilidad neta que han } \\
\text { generado las ventas }\end{array}$ \\
\hline & & Estandar: $5 \%$ a $10 \%$ \\
\hline & Margen de utilidad operacional $=\frac{\text { Utilidad operacional }}{\text { Ventas }} * 100$ & $\begin{array}{l}\text { Denota la utilidad operacional que se generaron de } \\
\text { las ventas de manera porcentual }\end{array}$ \\
\hline & & Estandar: $<10 \%$ \\
\hline
\end{tabular}

Fuente: Cordoba-Padilla (2016). 


\section{La liquidez en tiempos de COVID-19}

Ante la emergencia sanitaria los presidentes de los distintos países han incorporado restricciones en donde la limitación de circulación de personas ha producido un efecto secundario en el Producto Interno Bruto, por cuanto la mayoría de las actividades económicas a nivel mundial han tenido que ser paralizadas y en la actualidad operan bajo restricciones; debido a este escenario, la venta de bienes y servicios ha disminuido de forma drástica lo que provoca una crisis de liquidez tanto en las grandes como pequeñas y medianas empresas (Gómez \& De Vito, 2020).

Por otro lado, cabe recalcar que el Banco Mundial (BM) ha desarrollado proyectos en apoyo a los países de América Latina para responder al impacto económico y social causado por la COVID-19 mediante reorientación de fondos ya existentes, entre ellos está la distribución de alrededor de 4.600 millones de dólares para fortalecer los sistemas de salud de la región y con ello mitigar el impacto económico de la pandemia. Así mismo, se provee que dentro de los próximos 15 meses el BM proporcione asistencia a los países en desarrollo con 160.000 millones de dólares (Banco Mundial, 2021).

La COVID-19 ha afectado de manera significativa tanto a las grandes como a las pequeñas economías, a pesar de ello, las autoridades de cada país se han empeñado en disminuir la curva pandémica pues ahora inicia un nuevo reto para ellos, el mismo que consiste en ablandar el deterioro económico que ha provocado la actual pandemia.

Una estrategia necesaria en la situación actual para las pequeñas y medianas empresas es la implementación del presupuesto de tesorería que es una herramienta que tiene como finalidad gestionar planificar y controlar el activo circulante, para obtener un saldo de liquidez que se enfoque en determinar de manera clara la financiación, inversiones y pagos corrientes, lo que optimiza el control de los recursos en un periodo determinado, dichos presupuestos pueden estar diseñados de manera trimestral, semestral o anual esta periodicidad dependerá de cada empresa (Arguedas-Sanz, González-Arias, \& Oliver-Yébenes, 2009). 
Ante estas circunstancias, es necesario que los propietarios de cada negocio se enfoquen en tomar medidas correctivas direccionadas a la gestión financiera y económica que permitan reactivar sus actividades y recuperar la liquidez de sus organizaciones, entre varias medidas la principal es buscar el financiamiento externo y para ello, es importante planificar de manera organizada, así mismo, es conveniente incorporar políticas de control y aplicación de presupuestos flexibles, razonables y aplicables a la organización.

\section{METODOLOGÍA}

La presente investigación fue de tipo descriptivo con diseño no experimental, se basó en un análisis profundo en cuanto a la gestión financiera y la liquidez. Las técnicas aplicadas fueron la observación y la entrevista; y, como instrumentos se utilizaron una guía de observación y un cuestionario. El universo fue de 47 personas, conformado por 46 socios y 1 persona administrativa de la Cooperativa, la investigación se aplicó al 100\% del universo por ser reducido (Hernández- Sampieri, Fernández- Collado, \& Baptista- Lucio, 2014).

\section{RESULTADOS}

A continuación, se presentan los principales resultados obtenidos en el diagnóstico:

Riesgo de liquidez: una empresa puede contar con mucha riqueza en activos fijos y mercaderías, a pesar de ello, puede tener un alto riesgo de liquidez, por cuanto no puede convertirlo en circulante para cubrir sus obligaciones inmediatas. Durante la pandemia COVID - 19 la mayoría de empresas se vieron afectadas en su economía de manera inesperada al no generar ingresos por sus actividades operativas, viéndose en la necesidad de suspender sus operaciones como es el caso de la Cooperativa 27 de Junio. Durante los meses de paralización se enfrentaron serios problemas de liquidez, al no generar ingresos de manera normal, esta situación retrasó el pago a terceros y la recuperación de valores vencidos, a pesar de lo antes indicado, el $80 \%$ de los socios 
desconocen el impacto económico que ha ocasionado la pandemia, mientras que, el 20\% menciona que si conocen las afectaciones en la cooperativa.

Financiamiento externo: corresponde a los recursos que una empresa ha obtenido de forma externa para ejecutar su actividad económica. Al respecto, el 100\% indica que no ha solicitado financiamiento externo, debido a la inestabilidad en el giro normal del negocio provocado por la pandemia.

Evaluación mediante indicadores financieros: los indicadores financieros permiten evaluar los resultados de las operaciones ejecutadas en una empresa. Al consultarles a los socios de la cooperativa si aplican indicadores financieros para evaluar su desempeño, el 100\% respondió que no lo hace.

Inversiones: las inversiones responden a la colocación de capital en actividades comerciales o financieras con la finalidad de obtener un rendimiento. Sobre esta dimensión de estudio, el $100 \%$ de encuestados afirman no disponer de recursos para destinarlos a actividades de inversión.

\section{PROPUESTA}

De acuerdo con los resultados encontrados, se propone un modelo de gestión financiera que permita mejorar e incrementar la liquidez de la cooperativa de producción y mercadeo de teja y ladrillo 27 de Junio. La propuesta contiene: diagnostico situacional, análisis financiero, objetivos estratégicos, estrategias financieras y presupuesto de tesorería. 
Componente 1. Diagnóstico situacional: se identificaron aspectos positivos y negativos que influyen en el funcionamiento de cooperativa, para este efecto, se aplicó la técnica FODA (ver tabla 2).

\section{Tabla 2.}

Matriz FODA

\begin{tabular}{|c|c|}
\hline Fortalezas & Debilidades \\
\hline $\begin{array}{ll}- & \text { Cumple con sus obligaciones tributarias a tiempo. } \\
\text { - } & \text { Mantiene un control de calidad permanente. } \\
\text { - } & \text { Posee un sistema contable para registral los } \\
\text { - } & \text { movimientos. } \\
\text { - } & \text { Tienen } \\
& \text { Tiendentificados a sus clientes potenciales }\end{array}$ & $\begin{array}{ll}\text { - } & \text { Falta de herramientas de análisis económico. } \\
\text { - } & \text { Falta de conocimiento sobre gestión financiera. } \\
\text { - } & \text { Falta de liquidez. } \\
\text { - } & \text { Poca inversión en capacitación. } \\
\text { - } & \text { Ineficiencia del paquete contable } \\
\text { - } & \text { Falta de conocimiento en procesos innovadores en } \\
& \text { el sector. }\end{array}$ \\
\hline Oportunidades & Amenazas \\
\hline $\begin{array}{ll}\text { - } & \text { Régimen tributario que beneficia a las pequeñas } \\
\text { empresas. } & \\
\text { - } & \text { Instituciones financieras que brindan prestamos } \\
\text { con tasas preferenciales para pequeñas empresas } \\
\text { - } \quad \text { Planes de incentivos para el crecimiento en las } \\
\text { empresas del sector popular y solidario. }\end{array}$ & $\begin{array}{ll}\text { - } & \text { Pandemia del COVID } 19 \\
\text { - } & \text { Gran número de empresas competidoras. } \\
\text { - } & \text { Competencia en precios y calidad de una empresa } \\
\text { local. }\end{array}$ \\
\hline
\end{tabular}

Elaboración: Los autores.

Componente 2. Análisis financiero: se propone aplicar un análisis financiero para evaluar la situación y desempeño de la cooperativa durante el año 2020, bajo los efectos de la pandemia, desde las perspectivas económicas y financieras, lo que permitirá conocer las condiciones reales de la entidad, y, por consiguiente, identificar circunstancias que puedan incidir en su normal funcionamiento (ver figuras $3,4,5$ ). 
Revista Interdisciplinaria de Humanidades, Educación, Ciencia y Tecnología

Año VII. Vol. VII. N². Edición Especial II. 2021

Hecho el depósito de ley: pp201602FA4721

ISSN-L: 2542-3029; ISSN: 2610-802X

Universidad Nacional Experimental Francisco de Miranda (UNEFM). Santa Ana de Coro. Venezuela

Alba Briggithe Jiménez-Díaz; Cecilia Ivonne Narváez-Zurita

\begin{tabular}{|c|c|c|c|c|c|}
\hline \multicolumn{6}{|c|}{ Cooperativa De Producción Y Mercadeo De Teja Y Ladrillo 27 De Junio } \\
\hline \multicolumn{6}{|c|}{ RUC: 1191736946001} \\
\hline \multicolumn{6}{|c|}{ Estado de Resultados } \\
\hline \multicolumn{6}{|c|}{ Del 01-01-2020 Al 31-12-2020 } \\
\hline \multicolumn{6}{|c|}{ Análisis horizontal } \\
\hline \multicolumn{6}{|c|}{ Moneda: Dólares } \\
\hline CÓDIGO & CUENTAS & $\begin{array}{c}\text { AL } 31 \text { DE } \\
\text { DICIEMBRE } \\
2020 \\
\end{array}$ & $\begin{array}{c}\text { AL } 31 \text { DE } \\
\text { DICIEMBRE } \\
2019 \\
\end{array}$ & $\begin{array}{l}\text { VARIACIÓN } \\
\text { ABSOLUTA }\end{array}$ & $\begin{array}{l}\text { VARIACIÓN } \\
\text { RELATIVA }\end{array}$ \\
\hline 4 & INGRESOS & $141,054.18$ & $71,735.08$ & $69,319.10$ & $96.63 \%$ \\
\hline 4.1 & VENTAS & $140,768.01$ & $71,473.87$ & $69,294.14$ & $96.95 \%$ \\
\hline 4.1 .01 & Ventas locales arcilla & $121,087.00$ & $64,037.00$ & $57,050.00$ & $89.09 \%$ \\
\hline 4.1 .02 & Ventas locales tarifa $12 \%$ & $14,402.09$ & $2,157.95$ & $12,244.14$ & $567.40 \%$ \\
\hline 4.1 .04 & Alquiler de maquinaria & $4,538.92$ & $4,538.92$ & - & $0.00 \%$ \\
\hline 4.1 .05 & Mensualidad de socios & 730.00 & 730.00 & - & $0.00 \%$ \\
\hline 4.1 .06 & Cuotas - multas & 10.00 & 10.00 & - & $0.00 \%$ \\
\hline 4.2 & INGRESOS VARIOS & 286.17 & 261.21 & 24.96 & $9.56 \%$ \\
\hline 4.2 .01 & Intereses ganados en ahorros & 86.07 & 64.13 & 21.94 & $34.21 \%$ \\
\hline 4.2 .02 & Otros ingresos & 200.02 & 197.00 & 3.02 & $1.53 \%$ \\
\hline 4.2 .03 & Redondeo por decimales & 0.08 & 0.08 & - & $0.00 \%$ \\
\hline 5 & GASTOS & $119,875.42$ & $72,669.75$ & $47,205.67$ & $64.96 \%$ \\
\hline 5.2 & GASTOS & $119,875.42$ & $72,669.75$ & $47,205.67$ & $64.96 \%$ \\
\hline 5.2 .01 & Gastos en personal & $22,846.95$ & $21,376.14$ & $1,470.81$ & $6.88 \%$ \\
\hline 5.2 .01 .01 & Sueldos, salarios y demás & $12,200.00$ & $12,200.00$ & - & $0.00 \%$ \\
\hline 5.2 .01 .02 & Aportes de seguridad social & $1,482.28$ & $1,482.28$ & - & $0.00 \%$ \\
\hline 5.2 .01 .05 & Honorarios personas naturales & $3,111.07$ & $2,550.00$ & 561.07 & $22.00 \%$ \\
\hline 5.2 .01 .06 & Notarios & 564.80 & 463.00 & 101.80 & $21.99 \%$ \\
\hline 5.2 .01 .09 & Alimentación al personal & $2,640.28$ & $2,132.34$ & 507.94 & $23.82 \%$ \\
\hline 5.2 .01 .10 & Fondos de Reserva & 250.02 & 250.02 & - & $0.00 \%$ \\
\hline 5.2 .01 .12 & Beneficios sociales décimo tercero & $1,016.70$ & $1,016.70$ & - & $0.00 \%$ \\
\hline 5.2 .01 .13 & Beneficios sociales décimo cuarto & 766.03 & 766.03 & - & $0.00 \%$ \\
\hline 5.2 .01 .14 & Beneficios sociales vacaciones & 808.30 & 508.30 & 300.00 & $59.02 \%$ \\
\hline 5.2 .01 .15 & Gasto de Seguro salud tiempo parcial & 7.47 & 7.47 & - & $0.00 \%$ \\
\hline 5.2 .02 & Gasto en materiales & $24,726.51$ & $14,138.08$ & $10,588.43$ & $74.89 \%$ \\
\hline 5.2 .02 .01 & Mantenimiento y reparación & $9,821.25$ & $5,293.13$ & $4,528.12$ & $85.55 \%$ \\
\hline 5.2 .02 .02 & Repuestos y herramientas & $5,428.94$ & $3,982.87$ & $1,446.07$ & $36.31 \%$ \\
\hline 5.2 .02 .03 & Combustibles & $4,392.13$ & $2,527.96$ & $1,864.17$ & $73.74 \%$ \\
\hline 5.2 .02 .04 & Lubricantes & $3,610.71$ & $1,245.92$ & $2,364.79$ & $189.80 \%$ \\
\hline 5.2 .02 .05 & Suministros y materiales & $1,473.48$ & $1,088.20$ & 385.28 & $35.41 \%$ \\
\hline 5.2 .03 & Gasto en servicios & $63,354.18$ & $31,469.08$ & $31,885.10$ & $101.32 \%$ \\
\hline 5.2 .03 .01 & Arriendo de inmuebles & $2,400.00$ & $1,200.00$ & $1,200.00$ & $100.00 \%$ \\
\hline 5.2 .03 .02 & Transporte de carga/fletes & $2,530.04$ & 852.04 & $1,678.00$ & $196.94 \%$ \\
\hline 5.2 .03 .05 & Agua potable & 35.86 & 20.65 & 15.21 & $73.66 \%$ \\
\hline 5.2 .03 .06 & Arrendamiento de sistemas & 480.00 & 240.00 & 240.00 & $100.00 \%$ \\
\hline 5.2 .03 .07 & Energìa eléctrica & 228.16 & 111.34 & 116.82 & $104.92 \%$ \\
\hline 5.2 .03 .08 & Telefonia fija & 877.91 & 463.72 & 414.19 & $89.32 \%$ \\
\hline 5.2 .03 .09 & Telefonia mivil & 722.49 & 351.52 & 370.97 & $105.53 \%$ \\
\hline 5.2 .03 .11 & Impuestos, contribuciones & $2,159.32$ & $1,800.48$ & 358.84 & $19.93 \%$ \\
\hline 5.2 .03 .15 & Intereses pagados por multas & 363.78 & 356.93 & 6.85 & $1.92 \%$ \\
\hline 5.2 .03 .16 & Comisiones bancarias & 38.44 & 11.17 & 27.27 & $244.14 \%$ \\
\hline 5.2 .03 .19 & Transporte de desalojo & $53,518.18$ & $26,061.23$ & $27,456.95$ & $105.36 \%$ \\
\hline 5.2 .04 & Gastos Varios & $6,156.37$ & $4,019.62$ & $2,136.75$ & $53.16 \%$ \\
\hline 5.2 .04 .01 & Otros gastos locales & 0.12 & - & 0.12 & 0 \\
\hline 5.2 .04 .02 & IVA que se carga al gasto & $3,895.55$ & $2,486.40$ & $1,409.15$ & $56.67 \%$ \\
\hline 5.2 .04 .03 & Gasto en varios & 400.92 & 97.65 & 303.27 & $310.57 \%$ \\
\hline 5.2 .04 .04 & Gastos de gestión & $1,168.48$ & 951.77 & 216.71 & $22.77 \%$ \\
\hline 5.2 .04 .06 & Otros gastos (no deducibles) & 411.30 & 303.80 & 107.50 & $35.39 \%$ \\
\hline 5.2 .04 .08 & Gasto de mivilización (vía) & 280.00 & 180.00 & 100.00 & $55.56 \%$ \\
\hline 5.2 .05 & Gasto alquiler de maquinaria & $2,744.99$ & $1,624.49$ & $1,120.50$ & $68.98 \%$ \\
\hline 5.2 .05 .01 & Gasto en control de tierra & 720.00 & 580.00 & 140.00 & $24.14 \%$ \\
\hline 5.2 .05 .02 & Gasto alquiler de maquinaria & $2,024.99$ & $1,044.49$ & 980.50 & $93.87 \%$ \\
\hline 5.2 .06 & Gastos financieros & 46.42 & 42.34 & 4.08 & $9.64 \%$ \\
\hline 5.2 .06 .01 & Gastos financieros & 46.42 & 42.34 & 4.08 & $9.64 \%$ \\
\hline & Utilidad o pérdida del periodo & $21,178.76$ & $1,041.60$ & $22,220.36$ & $-2133.29 \%$ \\
\hline
\end{tabular}

Figura 3. Análisis horizontal estado de resultados.

Elaboración: Los autores. 
Revista Interdisciplinaria de Humanidades, Educación, Ciencia y Tecnología

Año VII. Vol. VII. N² 2 Edición Especial II. 2021

Hecho el depósito de ley: pp201602FA4721

ISSN-L: 2542-3029; ISSN: 2610-802X

Universidad Nacional Experimental Francisco de Miranda (UNEFM). Santa Ana de Coro. Venezuela

Alba Briggithe Jiménez-Díaz; Cecilia Ivonne Narváez-Zurita

\begin{tabular}{|c|c|c|c|c|c|}
\hline \multicolumn{6}{|c|}{ Cooperativa De Producción Y Mercadeo De Teja Y Ladrillo 27 De Junio } \\
\hline \multicolumn{6}{|c|}{ RUC: 1191736946001} \\
\hline \multicolumn{6}{|c|}{ Estado de Situación Financiera } \\
\hline \multicolumn{6}{|c|}{ Del 01-01-2020 Al 31-12-2020 } \\
\hline \multicolumn{6}{|c|}{ Análisis horizontal } \\
\hline \multicolumn{6}{|c|}{ Moneda: Dólares } \\
\hline CÓDIGO & CUENTAS & $\begin{array}{c}\text { AL } 31 \text { DE } \\
\text { DICIEMBRE }\end{array}$ & $\begin{array}{c}\text { AL } 31 \text { DE } \\
\text { DICIEMBRE }\end{array}$ & $\begin{array}{l}\text { VARIACIÓN } \\
\text { ABSOLUTA }\end{array}$ & $\begin{array}{l}\text { VARIACIÓN } \\
\text { RELATIVA }\end{array}$ \\
\hline 1 & ACTIVOS & $168.117,76$ & $153.094,65$ & $15.023,11$ & $9,81 \%$ \\
\hline 1.01 .01 & Efectivo y Equivalentes al efectivo & $12.600,73$ & $1.157,73$ & $11.443,00$ & $988,40 \%$ \\
\hline 1.01 .01 .01 & Caja general & - & 56,54 & 56,54 & $-100,00 \%$ \\
\hline 1.01 .01 .03 & Banco de Loja & $12.077,20$ & 271,59 & $11.805,61$ & $4346,85 \%$ \\
\hline 1.01 .01 .04 & Coop de ahorro y crédito & 523,53 & 829,60 & 306,07 & $-36,89 \%$ \\
\hline 1.1 & ACTIVO CORRIENTE & $10.510,06$ & $7.929,95$ & $2.580,11$ & $32,54 \%$ \\
\hline 1.1 .03 & Cuentas por cobrar 2017 socia Nancy & - & 260,00 & 260,00 & $-100,00 \%$ \\
\hline 1.1 .04 & Cuentas por cobrar ayudas sociales & 410,00 & 345,00 & 65,00 & $18,84 \%$ \\
\hline 1.1 .10 & Crédito tributario Renta & 0,09 & 0,09 & - & $0,00 \%$ \\
\hline 1.1 .16 & Anticipo a proveedores & 319,89 & 79,78 & 240,11 & $300,97 \%$ \\
\hline 1.1 .17 & Cuentas por cobrar Martha Sánchez & $1.000,00$ & $1.000,00$ & - & $0,00 \%$ \\
\hline 1.1 .18 & Anticipo socio Carlos Ruìz & $4.650,00$ & $4.650,00$ & - & $0,00 \%$ \\
\hline 1.1 .20 & Otras cuentas por cobrar & 542,14 & 542,14 & - & $0,00 \%$ \\
\hline 1.1 .21 & Cuentas por cobrar mensualidades & 300,00 & 300,00 & - & $0,00 \%$ \\
\hline 1.1 .23 & Anticipo a empleados & $2.600,00$ & & $2.600,00$ & $0,00 \%$ \\
\hline 1.1 .29 & Cuenta por cobrar Efren Suquilanda & 187,94 & 252,94 & 65,00 & $-25,70 \%$ \\
\hline 1.1 .30 & Cuenta por cobrar Sr. Carlos Montaño & & 500,00 & 500,00 & $-100,00 \%$ \\
\hline 1.1 .31 & Cuentas por cobrar Bolivar Sánchez & 500,00 & - & 500,00 & $0,00 \%$ \\
\hline 1.2 & ACTIVO NO CORRIENTE & $145.006,97$ & $144.006,97$ & $1.000,00$ & $0,69 \%$ \\
\hline 1.2 .01 & Propiedad planta y equipo & $130.006,97$ & $130.006,97$ & - & $0,00 \%$ \\
\hline 1.2 .01 .01 & Terrenos & $71.057,52$ & $71.057,52$ & - & $0,00 \%$ \\
\hline 1.2.01.04 & Máquinaria y equipo & $105.140,00$ & $105.140,00$ & - & $0,00 \%$ \\
\hline 1.2 .01 .06 & Muebles y enseres & $2.126,59$ & $2.126,59$ & - & $0,00 \%$ \\
\hline 1.2 .01 .07 & Equipo de computación y software & $2.958,75$ & $2.958,75$ & - & $0,00 \%$ \\
\hline 1.2 .01 .09 & Equipo de oficina & 157,54 & 157,54 & - & $0,00 \%$ \\
\hline 1.2.01.12 & (-) Dep. Acum. Maquinaria & $49.143,54$ & $49.143,54$ & - & $0,00 \%$ \\
\hline 1.2.01.13 & (-) Dep. Acum. Equipos de computación & 795,41 & 795,41 & - & $0,00 \%$ \\
\hline 1.2.01.14 & (-) Dep. Acum. De Muebles y Enceres & $1.050,65$ & $1.050,65$ & - & $0,00 \%$ \\
\hline 1.2.01.15 & (-) Dep. Acum. De Equipo de oficina & 70,51 & 70,51 & - & $0,00 \%$ \\
\hline 1.2.01.16 & (-) Amortización de sotware & 373,32 & 373,32 & - & $0,00 \%$ \\
\hline 1.2 .02 & Activo a Largo Plazo & $15.000,00$ & $14.000,00$ & $1.000,00$ & $7,14 \%$ \\
\hline 1.2 .02 .04 & Acciones de la unión & $15.000,00$ & $14.000,00$ & $1.000,00$ & $7,14 \%$ \\
\hline 2 & PASIVO & $37.977,35$ & $45.174,60$ & $7.197,25$ & $-15,93 \%$ \\
\hline 2.1 & PASIVO CORRIENTE & $5.522,55$ & $9.085,97$ & $3.563,42$ & $-39,22 \%$ \\
\hline 2.1 .01 & Proveedores no relacionados locales & $3.232,57$ & $6.206,70$ & $2.974,13$ & $-47,92 \%$ \\
\hline 2.1.08 & Agente de retención en la fuente & 35,60 & 96,95 & 61,35 & $-63,28 \%$ \\
\hline 2.1 .08 .05 & S.R.I por pagar & 35,60 & 96,95 & 61,35 & $-63,28 \%$ \\
\hline 2.1 .09 & I.R. por por pagar del ejercicio & 103,93 & 106,93 & 3,00 & $-2,81 \%$ \\
\hline 2.1 .10 & Aporte patronal por pagar & 123,52 & 133,63 & 10,11 & $-7,57 \%$ \\
\hline 2.1 .11 & Aporte personal por pagar & 96,07 & 103,95 & 7,88 & $-7,58 \%$ \\
\hline 2.1 .12 & (-) $15 \%$ Participación a trabajadores & $1.032,15$ & $1.032,15$ & - & $0,00 \%$ \\
\hline 2.1 .18 & Décimo Tercer sueldo por pagar & 84,72 & 91,67 & 6,95 & $-7,58 \%$ \\
\hline 2.1 .19 & Décimo Cuarto sueldo por pagar & 313,99 & 313,99 & - & $0,00 \%$ \\
\hline 2.1 .21 & Cuenta por pagar acciones la unión & 500,00 & $1.000,00$ & 500,00 & $-50,00 \%$ \\
\hline 2.2 & PASIVO NO CORRIENTE & $32.454,80$ & $36.088,63$ & $3.633,83$ & $-10,07 \%$ \\
\hline 2.2 .01 & Otras cuentas por pagar & $32.366,17$ & $36.000,00$ & $3.633,83$ & $-10,09 \%$ \\
\hline 2.2 .02 & Liquidación de aportación de socios & 88,63 & 88,63 & - & $0,00 \%$ \\
\hline 3 & PATRIMONIO & $130.140,41$ & $107.920,05$ & $22.220,36$ & $20,59 \%$ \\
\hline 3.1 & CAPITAL & $130.140,41$ & $107.920,05$ & $22.220,36$ & $20,59 \%$ \\
\hline 3.1 .01 & Aporte de los socios & $1.909,26$ & $1.909,26$ & - & $0,00 \%$ \\
\hline 3.1 .01 .01 & Certificados de Aportación & 904,26 & 904,26 & - & $0,00 \%$ \\
\hline 3.1 .01 .02 & Ahorro para certificados & $1.005,00$ & $1.005,00$ & - & $0,00 \%$ \\
\hline 3.1 .02 & Reservas & $1.869,68$ & $1.869,68$ & - & $0,00 \%$ \\
\hline 3.1 .02 .01 & Reserva Legal & $1.869,68$ & $1.869,68$ & - & $0,00 \%$ \\
\hline 3.1 .03 & Resultados & $126.361,47$ & $104.141,11$ & $22.220,36$ & $21,34 \%$ \\
\hline 3.1 .03 .01 & Excedente de ejercicio anterior & $77.652,55$ & $77.652,55$ & - & $0,00 \%$ \\
\hline 3.1 .03 .02 & Utilidad o pérdida del ejercicio & $27.530,16$ & $27.530,16$ & - & $0,00 \%$ \\
\hline 3.1 .03 .03 & Utilidad o pérdida del ejercicio & $21.178,76$ & $1.041,60$ & $22.220,36$ & $-2133,29 \%$ \\
\hline & PATRIMONIO+PASIVO & $168.117,76$ & $153.094,65$ & $15.023,11$ & $9,81 \%$ \\
\hline
\end{tabular}

Figura 4. Análisis horizontal estado de situación financiera. Elaboración: Los autores. 
Revista Interdisciplinaria de Humanidades, Educación, Ciencia y Tecnología

Año VII. Vol. VII. N². Edición Especial II. 2021

Hecho el depósito de ley: pp201602FA4721

ISSN-L: 2542-3029; ISSN: 2610-802X

Universidad Nacional Experimental Francisco de Miranda (UNEFM). Santa Ana de Coro. Venezuela

Alba Briggithe Jiménez-Díaz; Cecilia Ivonne Narváez-Zurita

\begin{tabular}{|c|c|c|c|c|}
\hline Indicadores & Fórmulas & Rubros año 2020 & Resultado & Medición \\
\hline \multicolumn{5}{|c|}{ Liquidez } \\
\hline & Activo corriente & $10.510,06$ & \multirow{2}{*}{1,90} & \multirow{2}{*}{$>1,5$} \\
\hline Razón corriente & Pasivo corriente & $5.522,55$ & & \\
\hline Capital de trabajo & Activo corriente- Pasivo corriente & $10510,06-5522,55$ & $4.987,51$ & valores positivos $>1$ \\
\hline \multicolumn{5}{|c|}{ Endeudamiento } \\
\hline \multirow{2}{*}{ Nivel de endeudamiento } & \multirow{2}{*}{$\frac{\text { Pasivo total }}{\text { Activo total }} * 100$} & $37.977,35$ & \multirow{2}{*}{22,59} & \multirow{2}{*}{$<50 \%$} \\
\hline & & $168.117,76$ & & \\
\hline \multirow{2}{*}{ Estructura del capital } & \multirow{2}{*}{$\frac{\text { Pasivo total }}{\text { Patrimonio }} * 100$} & $37.977,35$ & \multirow{2}{*}{29,18} & $<50 \%$ capital propio \\
\hline & & $130.140,41$ & & $>50 \%$ con deudas \\
\hline \multirow[b]{2}{*}{ Impacto de carga financiera } & \multirow{2}{*}{$\frac{\text { Gastos financieros }}{\text { Ventas }}$} & 46,42 & \multirow[b]{2}{*}{0,00} & \multirow[b]{2}{*}{$<4 \%$} \\
\hline & & $140.768,01$ & & \\
\hline \multirow{2}{*}{$\begin{array}{l}\text { Concentración de } \\
\text { endeudamiento corto plazo }\end{array}$} & \multirow{2}{*}{$\frac{\text { Pasivo corriente }}{\text { Pasivo total }} * 100$} & $5.522,55$ & \multirow[b]{2}{*}{14,54} & $<50 \%$ capital propio \\
\hline & & $37.977,35$ & & $\begin{array}{l}>50 \% \text { pierde autonomia } \\
\text { con proveedores }\end{array}$ \\
\hline \multicolumn{5}{|c|}{ Rentabilidad } \\
\hline \multirow[b]{2}{*}{ Margen de utilidad bruto } & \multirow{2}{*}{$\frac{\text { Utilidad bruta }}{\text { Ventas netas }} * 100$} & $50.228,50$ & \multirow[b]{2}{*}{35,68} & \multirow[b]{2}{*}{$>40 \%$} \\
\hline & & $140.768,01$ & & \\
\hline \multirow{2}{*}{ Margen de utilidad neta } & \multirow{2}{*}{$\frac{\text { Utilidad neta }}{\text { Ventas }} * 100$} & $21.178,76$ & \multirow{2}{*}{15,05} & \multirow{2}{*}{$>10 \%$} \\
\hline & & $140.768,01$ & & \\
\hline
\end{tabular}

Figura 5. Ratios financieras.

Elaboración: Los autores.

Mediante la aplicación de ratios financieros que corresponden a la información del año 2020 se puede observar los siguientes resultados:

a) En la razón corriente se refleja que la cooperativa tiene la capacidad para cubrir sus obligaciones a corto plazo, lo que quiere decir que, por cada dólar adeudado cuenta con $\$ 1.90$ para cubrir sus obligaciones.

b) En el capital de trabajo se observa una cifra positiva superior a uno, lo que determina que una vez que se han deducido las obligaciones a corto plazo posee los recursos necesarios para cubrir sus gastos y continuar con el normal desarrollo de sus actividades. 
c) El nivel de endeudamiento indica que la cooperativa tiene un mínimo nivel de obligaciones por pagar, ya que se encuentra por debajo del estándar con un $22.59 \%$, debido a que durante el año 2020 se vieron en la necesidad de paralizar sus operaciones por la pandemia por lo que no recurrieron al financiamiento de proveedores y mantuvieron deudas antiguas.

d) La estructura de capital da como resultado $29.18 \%$, esto representa que la cooperativa financia sus obligaciones con capital propio, denotando el buen aprovechamiento de los recursos que los socios han aportado al capital.

e) El impacto de la carga financiera muestra la utilización del endeudamiento, en este caso representa el $0 \%$, ya que no ha recurrido al financiamiento con terceros para el desarrollo de sus actividades operacionales.

f) La concentración del endeudamiento a corto plazo representa el $14.54 \%$ evidenciando que la deuda de los pasivos corrientes ha sido cubierta con el capital propio, permitiéndole responder con sus obligaciones menores a un año.

g) El margen de utilidad bruto representa el $35.68 \%$, encontrándose por debajo del estándar, esto no es muy favorable, por cuanto representa el margen de utilidad sobre las ventas una vez deducidos los costos y gastos.

h) El margen de utilidad neta explica que por cada dólar vendido se obtuvo un $15.05 \%$ de ganancia, este resultado cumple con el estándar permitido, evidenciando la capacidad que tiene la cooperativa para convertir en beneficios los ingresos que recibe. 
Revista Interdisciplinaria de Humanidades, Educación, Ciencia y Tecnología

Año VII. Vol. VII. N² 2 Edición Especial II. 2021

Hecho el depósito de ley: pp201602FA4721

ISSN-L: 2542-3029; ISSN: 2610-802X

Universidad Nacional Experimental Francisco de Miranda (UNEFM). Santa Ana de Coro. Venezuela

Alba Briggithe Jiménez-Díaz; Cecilia Ivonne Narváez-Zurita

Componente 3. Objetivos estratégicos: Se establecieron objetivos de ingresos, gastos, inversión, financiamiento y control que permitirán incrementar su liquidez a corto mediano y largo plazo (ver tabla 3).

\section{Tabla 3.}

Objetivos estratégicos.

\begin{tabular}{|c|cl|}
\hline \multicolumn{2}{|c|}{ Objetivos estratégicos } \\
\hline Perspectivas & & \multicolumn{1}{c|}{ Objetivos } \\
\hline Financieras & - & Incorporar inversiones que aporten valor a la cooperativa. \\
& - & Buscar apalancamiento con instituciones financieras para reactivar la economía. \\
& - & Incrementar las ventas de contado y disminuir las ventas a crédito. \\
& - & Recuperar la cartera en menor tiempo. \\
& - & Diversificar los ingresos \\
\hline Clientes & - & Incorporar nuevos clientes. \\
& - & Identificar clientes potenciales. \\
& - & Incrementar la cuota del mercado \\
\hline Procesos internos & - & Incrementar e innovar la producción de teja y ladrillo. \\
& - & Dotar de los productos oportunamente. \\
& - & Otorgar servicios posventa. \\
\hline Innovación y & - & Incrementar capacitaciones para socios y personal administrativo. \\
aprendizaje & - & Incorporar sistemas de información. \\
& - & Satisfacer y retener al empleado. \\
\hline
\end{tabular}

Elaboración: Los autores.

Componente 4. Estrategias financieras: se plantean estrategias basadas en los objetivos institucionales como parte de la gestión para garantizar la permanencia de la cooperativa en el tiempo (ver tabla 4) 
Revista Interdisciplinaria de Humanidades, Educación, Ciencia y Tecnología

Año VII. Vol. VII. N²2. Edición Especial II. 2021

Hecho el depósito de ley: pp201602FA4721

ISSN-L: 2542-3029; ISSN: 2610-802X

Universidad Nacional Experimental Francisco de Miranda (UNEFM). Santa Ana de Coro. Venezuela

Alba Briggithe Jiménez-Díaz; Cecilia Ivonne Narváez-Zurita

Tabla 4.

Estrategias financieras.

\begin{tabular}{|c|c|c|c|c|}
\hline \multicolumn{5}{|c|}{ Estrategias financieras } \\
\hline Perspectivas & Objetivos Estratégicos & Estrategias & Recursos & Responsables \\
\hline \multirow[t]{5}{*}{ Financieras } & $\begin{array}{l}\text { Incorporar inversiones } \\
\text { que aporten valor a la } \\
\text { cooperativa }\end{array}$ & $\begin{array}{l}\text { Adquirir maquinaria a partir del segundo } \\
\text { semestre del año. }\end{array}$ & Recursos materiales & \multirow[t]{4}{*}{$\begin{array}{l}\text { Consejo de } \\
\text { administración } \\
\text { y vigilancia }\end{array}$} \\
\hline & $\begin{array}{l}\text { Apalancamiento r con } \\
\text { instituciones financieras } \\
\text { para reactivar la } \\
\text { economía }\end{array}$ & $\begin{array}{l}\text { Acceder a créditos bancarios } \\
\text { considerando la menor tasa de interés. }\end{array}$ & Recursos financieros & \\
\hline & $\begin{array}{l}\text { Incrementar las ventas a } \\
\text { contado y disminuir las } \\
\text { ventas a crédito }\end{array}$ & $\begin{array}{l}\text { El } 85 \% \text { de las ventas a contado y el } 15 \% \\
\text { a crédito. }\end{array}$ & Recursos financieros & \\
\hline & $\begin{array}{l}\text { Recuperación de cartera } \\
\text { en menor tiempo }\end{array}$ & $\begin{array}{l}\text { El } 40 \% \text { de las ventas a } 7 \text { días, el } 40 \% \text { a } \\
15 \text { días y el } 20 \% \text { a } 30 \text { días plazo. }\end{array}$ & Recursos financieros & \\
\hline & Diversificar los ingresos & $\begin{array}{l}\text { Expandir la producción y la oferta del } \\
\text { producto a nuevos mercados. }\end{array}$ & $\begin{array}{l}\text { Recursos humanos y } \\
\text { tecnológicos }\end{array}$ & Contador \\
\hline \multirow[t]{3}{*}{ Clientes } & $\begin{array}{l}\text { Incorporar nuevos y más } \\
\text { clientes }\end{array}$ & $\begin{array}{l}\text { Aplicar campañas publicitarias utilizando } \\
\text { la tecnología mediante difusiones por } \\
\text { medios locales y redes sociales. }\end{array}$ & $\begin{array}{l}\text { Recursos } \\
\text { tecnológicos }\end{array}$ & \multirow[t]{2}{*}{$\begin{array}{l}\text { Consejo de } \\
\text { administración } \\
\text { y vigilancia }\end{array}$} \\
\hline & $\begin{array}{l}\text { Mantener los clientes } \\
\text { potenciales }\end{array}$ & $\begin{array}{l}\text { Otorgar incentivos a los clientes de } \\
\text { mayor concurrencia. }\end{array}$ & Recursos financieros & \\
\hline & $\begin{array}{l}\text { Incrementar la cuota de } \\
\text { mercado }\end{array}$ & $\begin{array}{l}\text { Identificar y cubrir las necesidades del } \\
\text { cliente para ganar su fidelidad. }\end{array}$ & $\begin{array}{l}\text { Recursos } \\
\text { tecnológicos } \\
\text { humanos }\end{array}$ & Contador \\
\hline \multirow[t]{3}{*}{$\begin{array}{l}\text { Procesos } \\
\text { internos }\end{array}$} & $\begin{array}{l}\text { Incrementar e innovar la } \\
\text { producción de teja y } \\
\text { ladrillo }\end{array}$ & $\begin{array}{l}\text { Mantener suficiente stock de los } \\
\text { productos y crear nuevos productos. }\end{array}$ & Recursos materiales & $\begin{array}{l}\text { Consejo de } \\
\text { administración } \\
\text { y vigilancia }\end{array}$ \\
\hline & $\begin{array}{l}\text { Dotar de los productos } \\
\text { oportunamente }\end{array}$ & $\begin{array}{l}\text { Cumplir con los términos y condiciones } \\
\text { de entrega de los productos. }\end{array}$ & Recursos materiales & Contador \\
\hline & $\begin{array}{l}\text { Otorgar servicios de } \\
\text { posventa }\end{array}$ & $\begin{array}{l}\text { Incorporar servicios tecnológicos para el } \\
\text { pago de los clientes como recepción de } \\
\text { pagos por banca electrónica, tarjetas de } \\
\text { crédito y/ o débito. }\end{array}$ & $\begin{array}{l}\text { Recursos financieros } \\
\text { Y humanos }\end{array}$ & \multirow[t]{4}{*}{$\begin{array}{l}\text { Consejo de } \\
\text { administración } \\
\text { y vigilancia }\end{array}$} \\
\hline \multirow[t]{3}{*}{$\begin{array}{l}\text { Innovación y } \\
\text { aprendizaje }\end{array}$} & $\begin{array}{lr}\text { Incrementar } & \\
\text { capacitaciones } & \text { para } \\
\text { socios y y } & \text { personal } \\
\text { administrativo. } & \end{array}$ & $\begin{array}{l}\text { Establecer un cronograma trimestral de } \\
\text { capacitaciones para socios y personal } \\
\text { administrativo. }\end{array}$ & Recursos humanos & \\
\hline & $\begin{array}{l}\text { Incorporar sistemas de } \\
\text { información }\end{array}$ & $\begin{array}{l}\text { Incrementar los estándares de } \\
\text { comunicación del empleado para retener } \\
\text { al cliente adecuado }\end{array}$ & $\begin{array}{l}\text { Recursos financieros } \\
\text { Y humanos }\end{array}$ & \\
\hline & $\begin{array}{l}\text { Satisfacer y retener al } \\
\text { empleado }\end{array}$ & $\begin{array}{l}\text { Generar un clima laboral saludable entre } \\
\text { los empleados, mediante incentivos y } \\
\text { reconocimientos por sus logros }\end{array}$ & $\begin{array}{l}\text { Recursos financieros } \\
\text { Y humanos }\end{array}$ & \\
\hline
\end{tabular}

Elaboración: Los autores. 


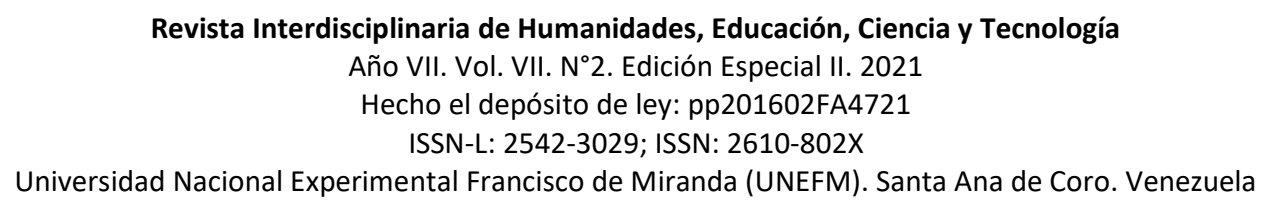

Alba Briggithe Jiménez-Díaz; Cecilia Ivonne Narváez-Zurita

Componente 5. Presupuesto de tesorería: En este componente se reflejan los ingresos y egresos del efectivo, para la proyección de las ventas y compras se utilizó el método de incremento, así como los porcentajes de recuperación de ventas a crédito a menor tiempo posible, mientras que, los pagos a proveedores se establecen en plazos mayores, con el propósito de garantizar la liquidez de la cooperativa (ver tabla 5). 
Hecho el depósito de ley: pp201602FA4721

ISSN-L: 2542-3029; ISSN: 2610-802X

Universidad Nacional Experimental Francisco de Miranda (UNEFM). Santa Ana de Coro. Venezuela

Alba Briggithe Jiménez-Díaz; Cecilia Ivonne Narváez-Zurita

\section{Tabla 9.}

Presupuesto de tesorería.

\begin{tabular}{|c|c|c|c|c|c|c|c|c|c|c|c|c|}
\hline Descripción & Enero & Febrero & Marzo & Abril & Mayo & Junio & Julio & Agosto & Setiembre & Octubre & Noviembre & Diciembre \\
\hline \multicolumn{13}{|l|}{ INGRESOS } \\
\hline Ventas netas & $14.035,98$ & $14.117,63$ & $14.199,76$ & $14.282,36$ & $14.365,45$ & $14.449,02$ & $14.533,07$ & $14.617,62$ & $14.702,65$ & $14.788,18$ & $14.874,21$ & $14.960,74$ \\
\hline Ventas al contado $(85 \%)$ & $11.930,58$ & $11.999,99$ & $12.069,80$ & $12.140,01$ & $12.210,63$ & $12.281,67$ & $12.353,11$ & $12.424,98$ & $12.497,26$ & $12.569,96$ & $12.643,08$ & $12.716,63$ \\
\hline $\begin{array}{|ll|}\text { Ventas al crédito }(15 \%) \\
\end{array}$ & & $2.105,40$ & $2.117,64$ & $2.129,96$ & $2.142,35$ & $2.154,82$ & $2.167,35$ & $2.179,96$ & $2.192,64$ & $2.205,40$ & $2.218,23$ & $2.231,13$ \\
\hline TOTAL INGRESOS & $11.930,58$ & $14.105,38$ & $14.187,44$ & $14.269,97$ & $14.352,99$ & $14.436,48$ & $14.520,47$ & $14.604,94$ & $14.689,90$ & $14.775,35$ & $14.861,31$ & $14.947,76$ \\
\hline \multicolumn{13}{|l|}{ EGRESOS } \\
\hline Compras totales & $3.488,37$ & $3.599,11$ & $3.713,37$ & $3.831,26$ & $3.952,89$ & $4.078,38$ & $4.207,86$ & $4.341,45$ & $4.479,28$ & $4.621,48$ & $4.768,20$ & $4.919,57$ \\
\hline Compras al contado $(75 \%)$ & $2.616,28$ & $2.699,33$ & $2.785,03$ & $2.873,45$ & $2.964,67$ & $3.058,79$ & $3.155,90$ & $3.256,09$ & $3.359,46$ & $3.466,11$ & $3.576,15$ & $3.689,68$ \\
\hline Gastos en personal & $1.377,56$ & $1.377,56$ & $1.377,56$ & $1.377,56$ & $1.377,56$ & $1.377,56$ & $1.377,56$ & $1.377,56$ & $1.377,56$ & $1.377,56$ & $1.377,56$ & $1.377,56$ \\
\hline Gasto en notarios & 42,00 & 42,00 & 42,00 & 42,00 & 42,00 & 42,00 & 42,00 & 42,00 & 42,00 & 42,00 & 42,00 & 42,00 \\
\hline Gasto en alimentación personal & 80,00 & 80,00 & 80,00 & 80,00 & 80,00 & 80,00 & 80,00 & 80,00 & 80,00 & 80,00 & 80,00 & 80,00 \\
\hline Gastos en servicios básicos & 155,00 & 155,00 & 155,00 & 155,00 & 155,00 & 155,00 & 155,00 & 155,00 & 155,00 & 155,00 & 155,00 & 155,00 \\
\hline Gasto en transporte & $3.670,00$ & $3.670,00$ & $3.670,00$ & $3.670,00$ & $3.670,00$ & $3.670,00$ & $3.670,00$ & $3.670,00$ & $3.670,00$ & $3.670,00$ & $3.670,00$ & $3.670,00$ \\
\hline Gasto arriendo de sistema contable & 40,00 & 40,00 & 40,00 & 40,00 & 40,00 & 40,00 & 40,00 & 40,00 & 40,00 & 40,00 & 40,00 & 40,00 \\
\hline Pago de tasas, impuestos y contribuciones & 280,00 & 100,00 & 360,00 & 100,00 & 100,00 & 100,00 & 110,00 & 140,00 & 170,00 & 190,00 & 240,00 & 290,00 \\
\hline Gasto en comisiones bancarias & 3,00 & 3,00 & 3,00 & 4,00 & 4,00 & 4,00 & 5,00 & 5,00 & 5,00 & 6,00 & 6,00 & 6,00 \\
\hline Compra de activos & & & & & & & $22.000,00$ & & & & & \\
\hline Gastos varios & 420,30 & 420,30 & 420,30 & 420,30 & 420,30 & 420,30 & 420,30 & 420,30 & 420,30 & 420,30 & 420,30 & 420,30 \\
\hline TOTAL EGRESOS & $8.824,14$ & $9.599,29$ & $9.972,67$ & $9.830,65$ & $9.951,34$ & $10.075,87$ & $32.215,35$ & $10.377,91$ & $10.544,68$ & $10.706,79$ & $10.902,38$ & $11.102,59$ \\
\hline SALDO DE CAJA & $3.106,45$ & $4.506,10$ & $4.214,77$ & $4.439,32$ & $4.401,64$ & $4.360,61$ & $-17.694,89$ & $4.227,03$ & $4.145,22$ & $4.068,57$ & $3.958,93$ & $3.845,17$ \\
\hline CAJA INICIAL & $15.000,00$ & $18.106,45$ & $22.612,55$ & $26.827,32$ & $31.266,64$ & $35.668,28$ & $40.028,90$ & $22.334,01$ & $26.561,04$ & $30.706,26$ & $34.774,82$ & $38.733,75$ \\
\hline FLUJO DE CAJAECONÓMICO & $18.106,45$ & $22.612,55$ & $26.827,32$ & $31.266,64$ & $35.668,28$ & $40.028,90$ & $22.334,01$ & $26.561,04$ & $30.706,26$ & $34.774,82$ & $38.733,75$ & $42.578,93$ \\
\hline Prèstamos bancarios obtenidos & & & & & & & $22.000,00$ & & & & & \\
\hline Pago capital e interes por préstamo & & - & & & & & & 560,80 & 560,80 & 560,80 & 560,80 & 560,80 \\
\hline \multicolumn{13}{|l|}{\begin{tabular}{|l} 
Intereses \\
\end{tabular}} \\
\hline FLUJO DE CAJAFINANCIERO & $18.106,45$ & $22.612,55$ & $26.827,32$ & $31.266,64$ & $35.668,28$ & $40.028,90$ & $44.334,01$ & $26.000,24$ & $30.145,46$ & $34.214,02$ & $38.172,95$ & $42.018,13$ \\
\hline
\end{tabular}

Elaboración: Los autores.. 


\section{CONCLUSIONES}

Un plan de continuidad en la actual situación de pandemia permite desarrollar una propuesta para mejorar la capacidad de recuperación de la cadena de suministros, acatamiento de las demandas legales y de los consumidores y posibilidad de responder a sucesos mayores de manera efectiva y con procesos seguros, desarrollar un proceso de gestión financiera permite generar ingresos, reducir los costos con un manejo eficiente de los recursos de las organizaciones, a la vez, gestiona aspectos significativos como la inversión y el financiamiento.

La Cooperativa de producción y mercadeo de teja y ladrillo 27 de Junio durante la pandemia COVID - 19 se vio afectadas en su economía por la falta de liquidez al no generar ingresos por sus actividades operativas, falta de planificación de inversiones anuales tanto en rendimientos financieros como en adquisición de activos fijos que permitan dinamizar las actividades normales del negocio, viéndose en la necesidad de suspender sus operaciones.

Para contrarrestar esta situación se plantea aplicar un modelo de gestión financiera que permita mejorar e incrementar la liquidez de la cooperativa de producción y mercadeo de teja y ladrillo 27 de Junio, esta propuesta parte de un diagnóstico situacional de la cooperativa un análisis financiero que permite plantear objetivos y estrategias que contribuyan ante imprevistos tales como: planes de inversión que aporten en la generación de ingresos que garanticen la rentabilidad y la liquidez de la organización, así como planes de financiamiento tanto de sector público como privado, que permitan reactivar la economía y estabilizar el negocio ante posibles riesgos para hacer frente a la crisis actual de manera eficiente y eficaz.

Ante la crisis económica presentada por la pandemia, se ha visto la necesidad de que las empresas desarrollen un plan de continuidad que les permita adelantarse a los sucesos y tener un plan de gestión financiera para prevenir riesgos. 


\section{REFERENCIAS}

Arguedas-Sanz, R., González-Arias, J., \& Oliver-Yébenes, M. (2009). Introducción a la gestión financiera sin animos de lucro. [Introduction to non-profit financial management]. Madrid: Economistas sin Fronteras.

Banco Mundial. (2021). Banco Mundial. [World Bank]. Recuperado de https://n9.cl/nsw2d

Caceres-Pineda, E. (2020). Efectos del segmento de clientes en el riesgo de liquidez de los fondos de inversión abiertos en Colombia [Effects of the customer segment on the liquidity risk of investment funds opened in Colombia]. Recuperado de https://n9.cl/zd96g

Cárdenas-Carreño, J. H., Erazo-Álvarez, J. C., Narváez-Zurita, C. I., \& Andrade-Mena, G. I. (2021). Plan Estratégico Institucional para de la junta de riego y drenaje "Manuel J. Calle" [Institutional Strategic Plan for the irrigation and drainage board "Manuel J. Calle"]. CIENCIAMATRIA, 7(12), 838-869. https://doi.org/10.35381/cm.v7i12.451

Casares, I., \& Lizarzaburu-Bolañoz, E. R. (2016). Instroducción a la gestión integral de riesgos empresariales. Enfoque: ISO 31000. [Introduction to comprehensive business risk management. Focus: ISO 31000]. Lima: PLATINIUM EDITORIALS.A.C. Recuperado de https://n9.cl//irbtc

Cepeda-Palacio, S. D., Velásquez-Estrada, L. J., \& Marín-Gómez, B. E. (06 de 07 de 2017). Análisis evaluativo del proceso de marketing en la internacionalización de pequeñas y medianas empresas alimentarias en Medellín. [Evaluative analysis of the marketing process in the internationalization of small and medium food companies in Medellín]. Estudios Gerenciales, 1. https://doi.org/10.1016/j.estger.2017.06.006

Chávez, G. (2020). Evaluación del riesgo empresariales:Indicadores para medir los recursos de la empresa actualmente y en post pandemia [Business risk assessment: Indicators to measure current and post-pandemic business resources]. Crecer Empresarial: Journal of Management and Development., (03). Recuperado a partir https://journalusco.edu.co/index.php/cempresarial/article/view/2852

Coba, G. (2020). Las empresas enfrentan falta de liquidez por la emergencia sanitaria. [Companies face lack of liquidity due to the health emergency]. Obtenido de https://n9.cl/ti506 
Comisión Económica para América Latina y el Caribe (CEPAL). (02 de 07 de 2020). Sectores y empresas frente al COVID-19: emergencia y reactivación. [Sectors and companies facing COVID-19: emergency and reactivation]. Recuperado de https://n9.cl/b493s

Cordoba-Padilla, M. (2016). Analisis Financiero. [Financial analysis]. Bogotá: Ecoe Ediciones.

Deloitte. (2017). Everything is in preparation. https://n9.cl/y953d

Efiempresa. (2021). Rentabilidad en tiempos de crisis. Recuperado de https://n9.cl/0c69s

Erazo-Álvarez, J. C., López-Intriago, C. F., Narváez-Zurita, C. I., \& Moreno, V. P. (2020). Gestión financiera basada en la creación de valor para el sector microempresarial de servicios. [Financial management based on the creation of value for the microbusiness services sector]. KOINONIA, 5. http://dx.doi.org/10.35381/r.k.v5i10.701

Espinoza-Carrión, D. I., Narváez-Zurita, C. I., Erazo-Alvarez, J. C., \& Machuca-Conteras, M. D. (2019). La estrategia financiera como herramienta funcional para la gestión de liquidez en las organizaciones. [Financial strategy as a functional tool for liquidity management in organizations]. CIENCIAMATRIA, 5(1), 502-532. https://doi.org/10.35381/cm.v5i1.278

Fajardo-Ortiz, M., \& Soto-González, C. (2018). Gestión Financiera Empresarial. [Business Financial Management]. Machala: UTMACH.

García-Nava, J. A., \& Paredes-Hernández, L. M. (2018). Estrategias Financieras Empresariales. México: Patria.

Gómez, J. P., \& De Vito, A. (2020). COVID-19. Cómo prevenir una crisis mayor por la falta de liquidez de las empresas. Recuperado de https://n9.cl//nqw9

Hernández- Sampieri, R., Fernández- Collado, C., \& Baptista- Lucio, M. d. (2014). Metodología de la investigación. [Investigation methodology]. Mexico DF: Mc GrawHill.

Lawrence, G., \& Chad, Z. (2016). Principios de administraciòn financiera. México: Pearson Educación. 
Palomo-Urrutia, E. A. (2016). El modelo de gestión financiera y el proceso para la toma de decisiones de la empresa CALZALONA S.A. de la ciudad de Ambato en el año 2015. Recuperado de https://repositorio.uta.edu.ec/handle/123456789/23875

Secretaria Técnica Planifica Ecuador. (2020). Efectos de la emergencia sanitaria en las organizaciones de la economía popular y solidaria. [Effects of the health emergency on the organizations of the popular and solidarity economy]. Ecuador. Obtenido de www.planificación.gob.ec

Superintendencia de Economía Popular y Solidaria (SEPS). (04 de 04 de 2021). Conoce la Economía Popular y Solidaria. Recuperado de https://n9.cl/sppc7

Tax Service \& TFC Consultores Corporativos. (2020). Tax Service. Recuperado el 10 de 06 de 2021, de ¿Como afecta en la contabilidad el COVID-19? [¿How does COVID-19 affect accounting?]: https://n9.cl/aivc7

Zambrano-Vera, T. I., Bernal-Alava, Á. F., Cedeño-Marcillo, G. M., Velásquez-Giler, C., Hormaza-Muñoz, Z., Santana-Castro, L. A., \& Chiriboga-Mendoza, F. (2018). Administracion Financiera para Pymes. [Financial Administratios for Pymes]. Manabí: Universidad Laica Eloy Alfaro de Manabí.

Zapata-Sánchez, P. (2017). Contabilidad genera: Con base en las normas internacionales de informaciòn financiera (NIIF). Bogotà, Colombia: Alfaomega Colombiana S.A. 